\title{
READERS
}

Journal of Management Info (JMI)

ISSN:2313-3376

www.readersinsight.net/jmi

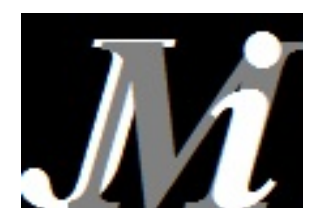

\section{Consequences of capital formation, trade liberalization on the economic growth: Pakistan's experience}

\author{
Anjum lqbal ${ }^{1}$, Nadia Bukhari* \\ ${ }^{1,2}$ Anjum Iqbal COMSATS Institute of Information Technology, Department of Management Sciences, 43600, Attock, Pakistan \\ *Corresponding author: nadia_bukhari@comsats.edu.pk
}

Abstract

This study considers the long run relationship between the liberalization of trade, capital formation and the economic growth of Pakistan by using the time series data from 1975-2013. The main aim of this study is to examine how much liberalization of trade and capital formation affects the economic growth of Pakistan in long run. The approach that has been used for empirical analysis is Auto Regressive Distributed Lag (ARDL) model. Under the ADF test, capital formation (CF) is stationary at its first level but the trade openness (TO) and GDP is stationary at its first difference. Moreover, the granger casualty test is evident that there becomes a causal relationship between the trade openness and GDP. The result of this study shows that both the trade openness and the capital formation determined the economic growth in long run and they both have statistically significant effect on the GDP. Furthermore it has been depicted from the study that trade has a vital role in influencing the economic growth.

\section{ARTICLE INFORMATION}

Received: 25 January 2015

Revised: 25 February 2015

Accepted: 1 March 2015

DOI:

http://dx.doi.org//10.31580/jmi.v5i1.37

\section{Introduction}

The theoretical intent of this paper is to establish a relationship between the economic growth of the Pakistan and its liberalization of trade and the capital formation. And if we examine the past research, theoretically there become a positive similarity between them. If we just explain the trade liberalization then there become two portions the export and the second one is import. The main goal of every country is to minimize the cost of the production and to increase the efficiency and this is just due to export because export heighten the prosperity of the economy and the production cited by K Menyah (2014). But on some extent there becomes a different result for developed and under developing countries on the basis of liberalization of the trade and the capital formation. SA Solarin (2014) cited that the open mindedness in the trade with other countries, the formation of the capital has a decisive contact with the economic growth of the country.

If we analyze the calculations regarding Pakistan then that's become a mysterious fact that this country has a huge labor force on $10^{\text {th }}$ number in the world. And on the other hand after Gawadur Port project there become revolutionary changes in the openness of the trade, after these change in Pakistan from past two decades that become a first-rate opportunity to explore the area on research by using the given variables from the time span of 1975-2013.

For the statistical examination of the data ARDL model is used, that become most appropriate and accurate approach to measure the data and give better result for the testing of the data in the long run and the short run scenario. Miloud (2014) explore the relationship of the openness of the trade with the economic growth of the Algeria by using the model ARDL and gets two different result, first one is the significant relation of the openness and the development of the
Algeria but on the other hand by checking along with one more independent variable it gives a insignificant results.

The separate features of this paper is to explore all the significant and the relevant variables in the category of the macro-economic level which were not present in any other studies from the given time series data from 1975-2013.

\section{Literature review}

With respect to the theoretical background there is a decisive relationship between the economic growth and the international trade or the trade openness argued by the Andersen and Babulal (2008). (Gries,and Redlin, 2012) point out that the most controversial topic among the literature of the economic is the growth of an economy and the trade openness. But according to the most of the study there become a positive relationship between the economic growth of an agrarian and the openness.

Romer et.al (1993) opined out that potent determinant for the economic growth becomes the trade openness, and there become a confident relationship between the economic growth of a country and the trade openness. The monetry growth of a country affected by the capital formation pointed out by the Levine and Renalt (1992).

Due to the accumulation of the capital investments increase, and on the other hand employment creates due to these investments, and due to the additional level of the employments confidence in larger investments increase due to the higher matched of savings and this cycle positively influence the economic growth surmised by Adhikary (2010). Roberto, Linda and Norman (2009) concluded that the growth of the economy improved by the trade openness across the border if we concentrate on some integral reforms like governance, financial depth, public infrastructure, educational investments etc. Dollar,D and 
Kraay, A. (2001) pointed out that for constant growth and the mitigation of the poverty it's the responsibility of the country to play a vital role for enhancing the international trade. The relationship of the openness change across the different correlation but widely there become a positive relationship between the openness and the economic growth but this become change on the basis of the data rather it's the time series, cross-sectional or the panel data cited by the Harrison, A. (1996).

David, Wyn and Peter (2002) argued that in the developing countries the growth has been impacted by the liberalization and conclude the four points that why it's become inconsistency among the affect of growth on the liberalization among the previous research. The developing countries pursue and ratify the liberalization and the trade openness to build up the living standards of the population and to boost up the economic growth of the country argued by (N.Elahi, Zahid and Mehboob).

Belloumi, M (2014) concluded that the trade openness and the capital formation has a positive and momentous effect on the economic growth but on the other hand there become a insignificant and confident of the federal direct investments on the economic growth of the country with respect to nigeria. Nasim S and Turkhan A (2004) argues that exports lead to increase the economic growth of the country but its counter term import is totally different and that's not ture for import. And between import and exports there is no significant influence.

The relationship between the exports and economic growth becomes fluctuate from nation to nation but the exports have the significant and the positive influence on the economic growth cited by Nikolaos Dritsakis (2006). Muhammad Zahir Faridi (2012) cited that main economy generating indicator for Pakistan is the agricultural export. But there is a significant and the negative relationship between the economic growth and the agricultural export and further it is suggested for Pakistan that the promoted exports are the non agricultural.

Veeramani (2009) concluded that with increase in the ratio of the imports will leads to increase in the economic growth of the country and the countries that import the products which are highly productive and profitable becomes enjoy huge increment in economic growth. Mohd F and Nanthakumar L (2011) point out the mysterious relationship between the import and the economic growth. Economic growth is indirectly influenced by the imports but on the other hand there is a direct influence of the economic growth on the imports.

The main feature of the formation of the capital is stock market and in modern economy stock market plays a vital role in the prosperity, advancement and the development of the country, therefore a beneficial link between the stock market and economic growth argues by Ajayi N.O and Owolabi A (2013). Ugwuegbe S andUruakpa P (2013) concluded that economic growth has a negative relationship with the interest rate and the inflation, but significant and positive relationship for the stock market and on other hand there's become a long run relationship between the growth of the economy of a country and the capital formation.

\section{Construction of variables}

Economic growth of the most of country judge by the GDP of the country, it's the best scale to measure the economy of the country just like others. Most of the world class researchers use GDP as a scale of the economic growth in there renowned papers. If we go through the history of the world economy then it's the fact that GDP use as indictor of the growth of the economy after the era of the World War II. Because the era during the World War II become the depressed era in the history of the world economy and in this situation GDP becomes use as a tool for the better and the efficient planning of the economic growth and the production of the industry.

Yanikkaya (2002) worked on a study of cross countries to investigate a relationship of the economy of the country and the country import, export. For the purpose of the economic growth of the country the indicator used by the researcher is the GDP, that how much effect of the barriers regarding trade on the GDP of the country. Claudia et.al
(2009) measure the relationship among the economic growth of the country and the internationally openness among the different countries, taking GDP as the indicator of the growth of the economy. And internationally there become a huge difference among different countries GDP according to the openness from the government. Levine and Renalt (1992) inspect the economic growth by taking GDP as an indicator and affect of the capital formation on it.

Adegboyega et.al (2014) measures the impact of the trade openness on the development of a country and the indicator for the measurement of the capital formation is the Gross Fixed Capital Formation. The liberalization of the trade becomes not catastrophic for the economic growth of a country measure by Fiestas (2005). Tahir et.al (2013) also discuss a decisive relationship between the liberalize trade and the growth of an economy.

Gungor Turan (2014) also studied the link between the broad mindedness of the exchange from distinctive nations and their effect on the money related development of the nation, by taking import and export as a gauge for the openness of the trade. (Gries,and Redlin, 2012) also adopt the import and export as an indicator for the liberalization of the trade among the different countries and discuss their link for the economical development of the country.

\section{Econometric specification}

The main purpose of the study is to examine the relationship between the economic growth of the country with the formation of the capital and the liberalization regarding trade of the country. The main purpose of the econometric model is to measure the reliability of the relationship that has been shown in the given research. Sadia et al. (2014) make use of the econometric equation with the rate connected with inflation plus the liberalization in the trade for a state within the monetary increase in the state.

Using the monetary increase of a unique state, their national strong purchase plus the trade openness Adegboyega et al. (2014) possesses utilized an equation with the effective in addition to efficient benefits. Chadha et al. (2014) furthermore review the connection between the economical increase as well as the openness of the trade using the econometric picture. Nafeesa et al. (2014) likewise reviewed the partnership relating to the international direct investment, liberalization from the trade and the financial growth from the nation by using the econometric situation. Omer et al. (2014) also examined a relation to the foreign direct investment as well as the monetary expansion through the particular econometric situation.

The econometric style for the liberalization from the business, creation from the money along with the liberalization of the trade from the region presented seeing that beneath,

$$
G D P=\alpha+\varphi_{1}(T O)+\varphi_{2}(C F)+\varepsilon
$$

The ARDL limits testing methodology of co-integration is produced by Pesaran (1999) and Shin and Pesaran et al (2001). Firstly, this system is more straightforward than different routines for cointegrating as like Johansen and Juselius (1990). Basically this become different for the long run and the short run for different each variable, that as been used in the given study. There become different advantages due to which the ARDL model is used for the interpretation of the statistical data which are given as under. (i) The ARDL headed no requirement for all the variables in the framework be of equivalent request of joining, (ii) It is a productive estimator regardless of the fact that examples are little and a portion of the regressors are endogenous, (iii) it permits that the variables may have diverse ideal slacks, (iv) it utilizes a solitary lessened structure mathematical statement.

Economic growth (GDP) $=\alpha+\varphi_{1}$ Trade openness $+\varphi_{2}$ Capital Formation $+\varepsilon$

\begin{tabular}{|l|l|}
\hline (GDP) & $\begin{array}{l}\text { Right here the real GDP is utilizing as the sign for that } \\
\text { rating of the monetary growth. Additional it is employ as } \\
\text { dependent varied from the presented circumstances. }\end{array}$ \\
\hline Trade & Trade openness is used as the independent variable. \\
\hline
\end{tabular}




\begin{tabular}{|l|l|}
\hline $\begin{array}{l}\text { Openness } \\
\text { (TO) }\end{array}$ & $\begin{array}{l}\text { And the scale of the measure for the trade openness in } \\
\text { the given research is to divide the real GDP from the } \\
\text { import and the export. }\end{array}$ \\
\hline $\begin{array}{l}\text { Capital } \\
\text { formation } \\
\text { (CO) }\end{array}$ & $\begin{array}{l}\text { Further the capital formation here also use as } \\
\text { independent variable and the scale for the } \\
\text { measurement of the capital formation is the gross fixed } \\
\text { capital formation. }\end{array}$ \\
\hline
\end{tabular}

The equation for the estimation of the ARDL framework is given as under, Equation (1)

$$
\Delta \mathrm{GDP}_{(\mathrm{i})}=\rho+\sum_{i=1}^{p} \phi_{0} \Delta \mathrm{GDP}_{(\mathrm{t}-\mathrm{i})}+\sum_{i=1}^{p} \varphi 1 \Delta \mathrm{T}_{\mathrm{t}-\mathrm{i}}+\sum_{i=1}^{p} \varphi 2 \Delta
$$

In this equation, we have two parts; first part is the calculation of the lag and in second part $\lambda$ show the long run relationship. By regressing the given ARDL model we have different values based on these values we check the long run relationship by the F-test. The given hypothesis for this test is given as under.

$\mathrm{H}_{0}=: \quad \lambda_{1}=\lambda_{2}=\lambda_{3}=0$ (There become no existence of long run relationship)

$\mathrm{H}_{1}=: \lambda_{1} \neq 0, \lambda_{2} \neq 0, \lambda_{3} \neq 0$ (Existence of long run relationship)

When there become a solid findings regarding establishment of the long run relationship then after this we estimates ECM.

Equation (2)

$$
\Delta G D P_{(i)}=\rho+\sum_{i=1}^{p} \varphi 0 \Delta G D P_{(t-i)}+\sum_{i=1}^{p} \varphi_{1} \Delta T O_{t-}
$$

After this we measure the ECM that shows the effects of the short term variables shock due to which adjustments has been taken on long run.

\section{Empirical result}

The ARDL strategy is generally used to test the co integration among the variables under thought. The application of the strategy obliges the accompanying key steps, firstly to escape spurious relationship by checking its stationary. Secondly the choice for the ideal request of slacks, third one is to test the long run relationship of the given variables and this is check through F-test. And then the next step is to estimate the coefficient of the long run and the short run and last one is to check the perfection of the given model. Under the Augmented Ducky Fuller test (ADF) it is to evident that the three variables $\mathrm{CF}$, TO and GDP has been tested. The variable capital formation $(\mathrm{CF})$ is stationary at its level so there is no need to take first difference for checking its stationary level and trade openness (TO), economic growth (GDP) is not stationary at its first level and these variables become stationary at its first differences.

The given table 2 shows the results of the granger causality test that has been used to know about the causality of the direction. The given causality and the F-statistic have been used under the given statements of the null hypothesis. From the given table we interpret that for TO does not granger case GDP rejection chances more as compared to the GDP does not granger case TO.

The data has shown the long run results of the given data. In the given data the coefficient of the TO is .3381 and on the other hand statistically it has been significant which has been interpreted that $1 \%$ increase in the trade openness will lead to $.33 \%$ increase in the GDP of Pakistan in long run. And on the other hand the coefficient of the $\mathrm{CF}$ is .3251 and has been statistically significant relationship with the
GDP which shows that $1 \%$ increase in the capital formation will lead to $.32 \%$ increase in GDP. If we check at the lower level of the table it's consist of the values that has been checked for the diagnostic statistics. And the given diagnostics test statistics shows that there become no serious effect of serial correlation and the hetroskedasticity. And this diagnostic test statistics also clear the functional from and the normality of the given data.

The short run results has been shown in table 4 which implies that all of the variables including TO, CF has been significant by statistically. And on the other hand $\mathrm{ECM}_{\mathrm{t}-1}$ that has been calculated in the table becomes true and fair in sign that is -.0714 and its shows that there become $.07 \%$ of the disequilibrium in the trade, GDP becomes adjusted back current year long run equilibrium with respect to the previous year. $\mathrm{R}^{2}$ of the given data shows that the given model become fit for the given variables testing.

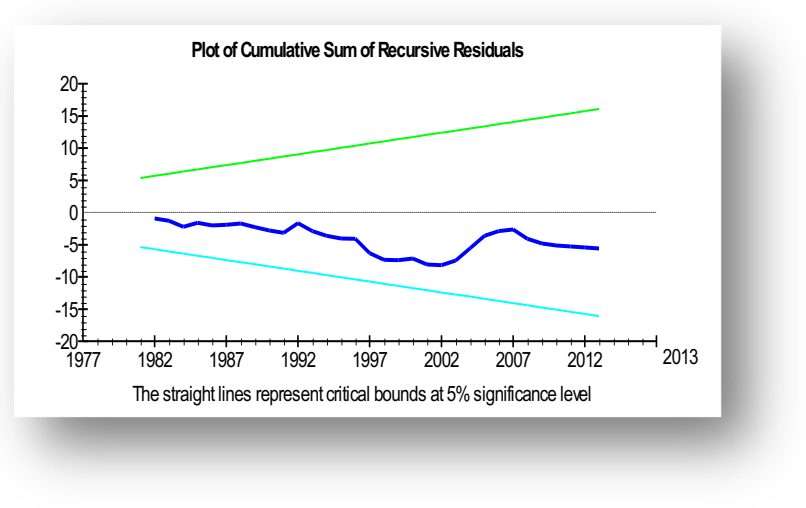

Based on the ARDL model that last stage that has been use for the given process is to test the stability of the given model that has been tested. The given fig 1 shows the recursive residuals of the cumulative sum, which shows that all the statistics that has been calculated within the given critical bound. As we know that this technique check the stability of the ECM that has been mentioned in the equation no 2 so by the given finding it's implies that all of the coefficient that has been tested in the ECM model become stable.

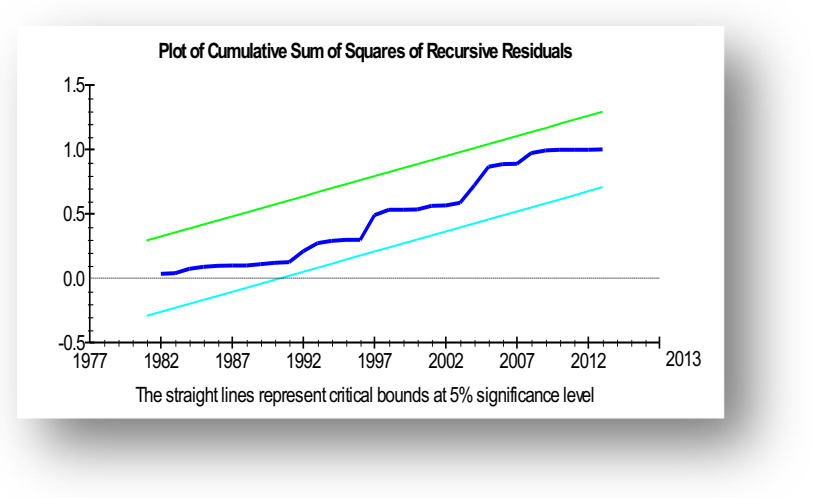

The graph in the figure 2 shows the cumulative sum of squares of recursive residuals technique results that all of the given statistics are in the critical bound and the given ECM model become stable with the given related variables.

\section{Conclusion}


The ultimate goal of this study is to check the relationship between the trade, capital formation and the economic growth of Pakistan with a time series of 1975-2013. Basically the hypothesis that's become pillar of the study has been tested by the renowned technique that is ARDL framework. Both independent variables have shown a significant relationship by the given statistics. The granger causality test elaborated that the given model is stable. And it has been depicted by the given empirical analysis that trade become determined the economic growth of Pakistan in long run.

\section{Policy making}

This study become helpful to examine and analyze the promoting measures of export and on other hand how to adjust the ration of import in a balanced way. And also to examine for the corrective measures to achieve an overwhelming benefits from trade for the country. By the contribution of law makers the policies regarding trade openness could improved that become much influencing for the economic growth of Pakistan. Basically this is not the borderline or the ends of research, rather this study become a base study for the more research with different ideas.

\section{References}

Adhikary, B. K. (2010). FDI, trade openness, capital formation, and economic growth in Bangladesh: a linkage analysis. International Journal of Business and Management, 6(1), p16.

Andersen, L., \& Babula, R. (2008). The link between openness and long-run economic growth. Journal of International Commerce and Economics, 1 , $1-20$.

Bibi, S., Ahmad, S. T., \& Rashid, H. (2014). Impact of Trade Openness, FDI, Exchange Rate and Inflation on Economic Growth: A Case Study of Pakistan. International Journal of Accounting and Financial Reporting, $4(2)$.

Belloumi, M. (2014). The relationship between trade, FDI and economic growth in Tunisia: An application of the autoregressive distributed lag model. Economic Systems.

Buch, C. M., \& Toubal, F. (2009). Openness and growth: The long shadow of the Berlin Wall. Journal of Macroeconomics, 31(3), 409-422.

Chang, R., Kaltani, L., \& Loayza, N. V. (2009). Openness can be good for growth: The role of policy complementarities. Journal of development economics, 90(1), 33-49.

Chadha, S. K., Singh, B., \& Natarajan, V. S. (2014). Interaction among foreign direct investment, economic growth and foreign trade: evidence from India and China. International Journal of Process Management and Benchmarking, 4(2), 145-166.

Dollar, D., \& Kraay, A. (2001). Trade, growth, and poverty. World Bank, Development Research Group, Macroeconomics and Growth.
Dritsakis, N., Varelas, E., \& Adamopoulos, A. (2006). The main determinants of economic growth: An empirical investigation with Granger causality analysis for Greece. European Research Studies Journal, 9(3-4), 47-58.

Faridi, M. Z. (2012). Contribution of Agricultural Exports to Economic Growth in Pakistan. Pakistan Journal of Commerce \& Social Sciences, 6(1).

Fiestas, I. (2005). The effects of trade liberalization on growth, poverty and inequality. CILAE Nota técnica NT/04, 5 .

Greenaway, D., Morgan, W., \& Wright, P. (2002). Trade liberalisation and growth in developing countries. Journal of development economics, 67(1), 229-244.

Gries, T., \& Redlin, M. (2012). Trade Openness and Economic Growth: A Panel Causality Analysis. Center for International Economics, Working Paper Series, (2011-06).

Harrison, A. (1996), "Openness and growth: A time-series, cross-country analysis for developing countries. Journal of Development Economics, 48, p. $419-447$

Kogid, M., Mulok, D., Ching, K. S., Lily, J., Ghazali, M. F., \& Loganathan, N. Does Import Affect Economic Growth in Malaysia.

Levine, R., \& Renelt, D. (1992). A sensitivity analysis of cross-country growth regressions. The American economic review, 942-963.

Owolabi, A., \& Ajayi, N. O. (2013). Econometrics Analysis of Impact of Capital Market on Economic Growth in Nigeria (1971-2010). Asian Economic and Financial Review, 3(1), 99-110.

Romer, P. (1993). Idea gaps and object gaps in economic development. Journal of monetary economics, 32(3), 543-573.

Shirazi, N. S., Manap, T. A. A., \& Din, M. U. (2004). Exports and Economic Growth Nexus: the Case of Pakistan [with Comments]. The Pakistan Development Review, 563-581.

Shahbaz, M., Khan, S., \& Tahir, M. I. (2013). The dynamic links between energy consumption, economic growth, financial development and trade in China: fresh evidence from multivariate framework analysis. Energy Economics, 40, 8-21.

Tabassum, N., \& Ahmed, S. P. (2014). Foreign Direct Investment and Economic Growth: Evidence from Bangladesh. International Journal of Economics and Finance, 6(9), p117.

Turan, G., \& Seni, D. (2014). The Effect of Trade Openness on Economic Growth: Albanian Case. Academic Journal of Interdisciplinary Studies, 3(3), 193.

Ugochukwu, U. S., \& Chinyere, U. P. (2013). The Impact of Capital Formation on the Growth of Nigerian Economy. Research Journal of Finance and Accounting, 4(9), 36-42.

Veeramani, C. (2009). Impact of imported intermediate and capital goods on economic growth: A cross country analysis. Available at SSRN 1325181

Yanikkya, H. (2003). Trade openness and economic growth: a cross country empirical investigation. Journal of Development Economies, 72, 57-89. 